\title{
Minireview
}

\section{Will early detection of non-axillary sentinel nodes affect treatment decisions?}

\section{F Wärnberg*,' and N Bundred ${ }^{2}$}

'Department of Surgery, Uppsala University Hospital, Sweden; ${ }^{2}$ Department of Surgery, South Manchester University Hospital, UK

\begin{abstract}
Axillary lymph node involvement is the best prognostic factor for breast cancer survival. Staging breast cancers by axillary dissection remains standard management and is part of the UK national guidelines for breast cancer treatment. In the presence of involved axillary lymph nodes best treatment has been shown to be axillary clearance (Fentiman and Mansell, 199I), but clearly for women whose nodes are uninvolved avoidance of morbidity is optimal and this will be achieved by minimal dissection of the axilla. Thus, for node-negative women the introduction of the sentinel node biopsy technique may revolutionise the approach to the axilla. These will be women with mammographic screen detected small well and moderately differentiated tumours (Hadjiloucas and Bundred, 2000). The impact of sentinel node biopsy in women who have symptomatic large tumours is unproven, and around half of these women will require a second procedure to clear their axilla or radiotherapy as treatment. Even for those women found to have involved sentinel lymph nodes the ability to use early systemic chemotherapy followed by axillary clearance or radiotherapy may provide long-term survival gains. Sentinel node biopsy should not, however, become routine practice until randomised controlled trials have proven its benefit and safety in reducing morbidity. Several randomised controlled trials (including ALMANAC) are currently underway.

British Journal of Cancer (2002) 87, 69I-693. doi:I0.1038/sj.bjc.6600557 www.bjcancer.com
\end{abstract}

(c) 2002 Cancer Research UK

Keywords: breast cancer; non-axillary sentinel node; treatment

Sentinel node lymphoscintigraphy leads to the visualisation of hot radioactive nodes in sites other than the axilla in about $13 \%$ of all cases (range $2-35 \%$ in series using different injection techniques) (Cserni and Szekeres, 2001). Tanis and co-workers in this issue of the Journal report the detection of non-axillary sentinel nodes and its impact on treatment. Earlier studies where internal mammary (IM) lymph node dissection has been performed have shown IM node involvement in about $23 \%$ of breast cancer patients (Cserni and Szekeres, 2001). In the study by Tanis et al (this issue) the proportion of detected non-axillary node metastases was about $5 \%$ among all patients, which is similar to findings in other studies where lymphoscintigraphy has been used (Cserni and Szekeres, 2001; Dupont et al, 2001). Only patients with a visualised non-axillary sentinel node were biopsied but this low proportion of metastases might also reflect that breast cancer is detected at an earlier stage today. The proportion of involved nodes was 20$25 \%$ among those patients who underwent an IM or other nonaxillary sentinel node biopsy.

Centrally and medially located tumours have been reported to have a higher proportion of IM lymph node metastases compared to lateral tumours (Manji, 1982). However, in the overview of series undergoing extended radical mastectomy (Cserni and Szekeres, 2001) the range of IM lymph node involvement was $13.3-35.3 \%$ in lateral tumours and $19.5-32.6 \%$ in central and medial tumours. Tumour location alone is therefore not a reliable indicator of risk for IM lymph node metastases (Urban and Marjani, 1971; Donegan, 1977; Noguchi et al, 1998, 2000; Sugg et al, 2000; Cserni and Szekeres, 2001; Dupont et al, 2001).

*Correspondence: F Wärnberg; E-mail: fredrik.warnberg@kirurgi.uu.se Received I4 June 2002; accepted I5 July 2002
The detection of an involved sentinel node in non-axillary sites (predominantly IM nodes) is not necessarily of prognostic value or predictive of survival. The prognostic value of IM lymph node involvement alone is similar to the value of axillary lymph node involvement (Noguchi et al, 1993; Veronesi et al, 1999). However, the importance of finding a non-axillary sentinel node will mainly be dependent on it being the only involved node which occurs in less than $10 \%$ of cases where the IM nodes are involved (Donegan, 1977; Jansen et al, 2000). A small proportion of axillary node negative patients have IM node metastases but today, we are not able to predict which patients these are. The value of finding these metastases remains to be determined both regarding prognosis and affect on treatment decisions.

The detection of IM nodes or other non-axillary sentinel nodes is largely dependent on the method of injection of isotope and the use of lymphoscintigraphy to detect involved nodes. A peritumoural injection technique visualises IM lymph nodes in about $15-30 \%$ of women, whereas subdermal or subareolar injection of isotope does not seem to identify IM nodes (Kett et al, 1993; Borgstein et al, 1997, 2000; Roumen et al, 1999; Cserni and Szekeres, 2001; Shen et al, 2001; Tanis et al, 2001). The mammary gland and the overlying skin clearly show a common lymphatic pathway to the axilla and the same axillary sentinel node in most cases (Dupont et al, 2001), but they do not appear to both drain to the IM chain. The kinetics of different traces and the timing of the injection before surgery are also issues that influence the detection and successful localisation of an IM node, e.g. lymph drains more slowly after a peri-tumoural injection compared to after an intra-dermal sub-areolar injection. Furthermore, the preoperative intra-dermal injection of colloid blue dye quickly disappears and makes it more difficult to find very small IM nodes compared with an intra-tumoural or peri-tumoural injection espe- 
cially if the IM node dissection is performed at the end of an operation including axillary dissection and primary tumour excision. The use of blue dye alone should be discouraged as it gives sub-optimal imaging for non-axillary sentinel nodes.

Although some authors have argued we should abandon lymphoscintigraphy (McIntosh and Purushotham, 1998) because most axillary sentinel nodes can be detected at operation by gamma-probe, its discontinuation would preclude the detection of IM nodes or non-axillary sentinel nodes. Thus, lymphoscintigraphy is particularly crucial for medial tumours in the breast in young women less than 70 years of age where chemotherapy may be indicated if a positive node is found in a non-axillary sentinel node but not in the axilla. However, it must also be recognised the treatment decisions are based on tumour characteristics (Goldhirsch et al, 1995). Large size, high grade, hormone receptor negativity and other prognostic factors generally indicate the need for chemotherapy regardless of node status at present. The nonaxillary node status will still add information on prognosis for these women but will not affect treatment decisions.

In the study by Tanis et al (this issue) patient management changed in $17 \%$ of patients with visualised non-axillary sentinel nodes. However, this may be an overestimation of the importance of non-axillary sentinel node biopsies. As shown in various randomised studies comparing Halsted mastectomy with extended mastectomy, the IM lymph node dissection by itself has no survival benefit (Lacour et al, 1976; Donegan, 1977; Veronesi et al, 1985, 1999). Another question to be answered is the role of radiotherapy as treatment to the IM chain. Thus far radiotherapy has not provided any survival advantage but the issue is still under study and a large European trial EORTC 22922 is investigating the effects of irradiation on the IM and medial supraclavicular lymph nodes in terms of loco-regional control and survival (Lievens et al, 2001). The routine practice in the department of Tanis et al (this issue) was to irradiate the parasternal area if axillary nodes were involved. In a large proportion of the cases where management 'changed' the use of radiotherapy was decided on the basis of the IM node status; a therapy that is unproven. Furthermore, eight out of 11 patients with isolated non-axillary lymph node metastases had tumours larger than $1 \mathrm{~cm}$ and would therefore have been offered adjuvant hormonal treatment according to many treatment guidelines anyway. The routine use of immunohistochemistry in addition to H\&E staining to detect nodal micro-metastases is not accepted practice in many centres and additionally, the prognostic value of metastases lesser than $2 \mathrm{~mm}$ in size is not proven (Yarbro et al, 1999). Thus the value of treating such findings is unknown and itself justifies a clinical trial comparing adjuvant treatment with no adjuvant treatment for women with nodal micro-metastases.

The benefit of IM sentinel node biopsy has to be weighed against the possible morbidity caused by surgery, as women who undergo breast-conserving surgery will need a further medial incision over the sternum to biopsy the IM node. The lack of interest in the IM node means that many surgeons today have no experience of the procedure nor have they had to deal with the complications of the procedure such as haemo- or pneumothorax (Bembenek and Schlag, 2000). However, a few studies have shown that non-axillary sentinel node biopsy can be performed with few side effects and a relatively high success ratio (Jansen et al, 2000; Noguchi et al, 2000; Dupont et al, 2001) although this has to be confirmed in other centres and countries.

The value of detecting non-axillary lymph nodes by lymphoscintigraphy potentially improves the rationale for individualising optimal treatment strategy. Biopsy of an IM lymph node is necessary if lymphoscintigraphy indicates it is the sentinel node, though, it remains inappropriate to biopsy an IM node if it is not blue or hot on lymphoscintigraphy as IM node biopsy is not routine practice. First and foremost, data from randomised trials are required to demonstrate that sentinel node biopsy is reducing morbidity in axillary surgery. Once such data is available we will be able to determine if the identification of non-axillary sentinel lymph nodes contributes to treatment decisions significantly.

\section{REFERENCES}

Bembenek A, Schlag PM (2000) Lymph-node dissection in breast cancer. Langenbecks Arch Surg 385: 236-245

Borgstein PJ, Meijer S, Pijpers R (1997) Intradermal blue dye to identify sentinel lymph-node in breast cancer. Lancet 349: 1668-1669

Borgstein PJ, Meijer S, Pijpers RJ, van Diest PJ (2000) Functional lymphatic anatomy for sentinel node biopsy in breast cancer: echoes from the past and the periareolar blue method. Ann Surg 232: $81-89$

Cserni G, Szekeres JP (2001) Internal mammary lymph nodes and sentinel node biopsy in breast cancer. Surg Oncol 10: 25-33

Donegan WL (1977) The influence of untreated internal mammary metastases upon the course of mammary cancer. Cancer 39: 533-538

Dupont EL, Salud CJ, Peltz ES, Nguyen K, Whitehead GF, Ku NN, Reintgen DS, Cox CE (2001) Clinical relevance of internal mammary node mapping as a guide to radiation therapy. Am J Surg 182: 321-324

Fentiman IS, Mansel RE (1991) The axilla: not a no-go zone. Lancet 337: $221-223$

Goldhirsch A, Wood WC, Senn HJ, Glick JH, Gelber RD (1995) Meeting highlights: international consensus panel on the treatment of primary breast cancer. J Natl Cancer Inst 87: 1441-1445

Hadjiloucas I, Bundred NJ (2000) Axillary Surgery: is it necessary? The Breast 9: $2-4$

Jansen L, Doting MH, Rutgers EJ, de Vries J, Olmos RA, Nieweg OE (2000) Clinical relevance of sentinel lymph nodes outside the axilla in patients with breast cancer. Br J Surg 87: 920-925

Kett K, Szilagyi K, Schmidt L (1993) Lymph drainage from the breast to the parasternal lymph nodes. Orv Hetil 134: 1913-1915

Lacour J, Bucalossi P, Cacers E, Jacobelli G, Koszarowski T, Le M, RumeauRouquette C, Veronesi U (1976) Radical mastectomy versus radical mastectomy plus internal mammary dissection. Five-year results of an international cooperative study. Cancer 37: 206-214
Lievens Y, Poortmans P, Van den Bogaert W (2001) A glance on quality assurance in EORTC study 22922 evaluating techniques for internal mammary and medial supraclavicular lymph node chain irradiation in breast cancer. Radiother Oncol 60: 257-265

Manji MF (1982) Medial Internal mammary lymphoscintigraphy in breast carcinoma: possible significance in relation to current treatment. $J$ Can Assoc Radiol 33: 10-14

McIntosh SA, Purushotham AD (1998) Lymphatic mapping and sentinel node biopsy in breast cancer. Br J Surg 85: $1347-1356$

Noguchi M, Ohta N, Thomas M, Kitagawa H, Miyazaki I (1993) Risk of internal mammary lymph node metastases and its prognostic value in breast cancer patients. J Surg Oncol 52: 26-30

Noguchi M, Tsugawa K, Taniya T, Miwa K (1998) The role of internal mammary lymph node metastases in the management of breast cancer. Breast Cancer 5: $117-125$

Noguchi M, Tsugawa K, Miwa K (2000) Internal mammary chain sentinel lymph node identification in breast cancer. J Surg Oncol 73: 75-80

Roumen RM, Geuskens LM, Valkenburg JG (1999) In search of the true sentinel node by different injection techniques in breast cancer patients. Eur J Surg Oncol 25: $347-351$

Shen P, Glass EC, DiFronzo LA, Giuliano AE (2001) Dermal versus intraparenchymal lymphoscintigraphy of the breast. Ann Surg Oncol 8: $241-248$

Sugg SL, Ferguson DJ, Posner MC, Heimann R (2000) Should internal mammary nodes be sampled in the sentinel lymph node era? Ann Surg Oncol 7: $188-192$

Tanis PJ, Nieweg OE, Valdes Olmos RA, Kroon BB (2001) Anatomy and physiology of lymphatic drainage of the breast from the perspective of sentinel node biopsy. J Am Coll Surg 192: 399-409 
Urban JA, Marjani MA (1971) Significance of internal mammary lymph node metastases in breast cancer. Am J Roentgenol Radium Ther Nucl Med 111: $130-136$

Veronesi U, Cascinelli N, Greco M, Bufalino R, Morabito A, Galluzzo D, Conti R, De Lellis R, Delle Donne V, Piotti P, Sacchini V, Clemente C, Salvadori B (1985) Prognosis of breast cancer patients after mastectomy and dissection of internal mammary nodes. Ann Surg 202: 702-707
Veronesi U, Marubini E, Mariani L, Valagussa P, Zucali R (1999) The dissection of internal mammary nodes does not improve the survival of breast cancer patients. 30-year results of a randomised trial. Eur J Cancer 35: $1320-1325$

Yarbro JW, Page D, Fielding LP, Partridge EE, Murphy GP (1999) American joint committee on cancer prognostic factors consensus conference. Cancer 86: $2436-2446$ 